\title{
sciendo
}

RESEARCH PAPERS FACULTY OF MATERIALS

SCIENCE AND TECHNOLOGY IN TRNAVA

SLOVAK UNIVERSITY OF TECHNOLOGY

IN BRATISLAVA

2021, Volume 29, Number 49

DOI 10.2478/rput-2021-0021

\section{INCREASING THE EFFICIENCY OF A ROBOTIC CELL USING SIMULATION}

\author{
Martin JUHÁS ${ }^{1}$, Bohuslava JUHÁSOVÁ ${ }^{1}$, Eduard NEMLAHA ${ }^{1}$, \\ Dominik CHARVÁT ${ }^{2}$ \\ ${ }^{1}$ Slovak University OF TECHNOLOGY IN BRATISLAVA \\ FACULTY OF MATERIALS SCIENCE AND TECHNOLOGY IN TRNAVA \\ INSTITUTE OF APPLIED INFORMATICS, AUTOMATION AND MECHATRONICS \\ ULICA JÁNA BOTTU Č. 2781/25, 91724 TRNAVA \\ ${ }^{2}$ PROCUS S.R.O. \\ BUKOVINSKÁ 7316/3, 83106 RAČA \\ e-mail:martin_juhas@stuba.sk, bohuslava.juhasova@stuba.sk, eduard.nemlaha@stuba.sk, \\ charvatdominik@gmail.com \\ Received 23 August 2021, Accepted 13 October 2021, Published 24 November 2021
}

\begin{abstract}
The paper deals with the possibilities of increasing the efficiency of a robotic cell. The robot assembly station is a part of a multi-robotic workplace capable of performing solitary operations. The complete production cycle of the cell is subjected to a thorough analysis. Deficiencies, having a direct impact on cell efficiency, are identified. These shortcomings include redundant movements of the robotic arm, the absence of an inspection mechanism for the presence of assembly parts, and inefficient instructions of the production cycle algorithm. The identified deficiencies are eliminated using the CIROS simulation tool. The result of the adjustments is a global 11.4\% increase in the efficiency of the robotic cell in terms of time performance.
\end{abstract}

\section{Keywords}

Robotic cell, increase efficiency, simulation

\section{INTRODUCTION}

Today's modern industrial technologies, in accordance with the Industry 4.0 concept, are primarily based on the combination of modern technologies for information processing with control technology in industrial automation. Their advantages complement each other, and thus create forms of control technologies intended for the field of industrial production. Computer control mainly concerns the presetting and control of each step in the industrial production process with utilization of unified algorithmization elements. In this way, it is possible to ensure that all types of data in the production process can be collected and processed efficiently in a 
timely manner, and thus improve production efficiency and, as a result, achieve a comprehensive technology benefit for the company (Bartodziej, 2017), (Enyoghasi \& Badurdeen, 2021), (Pereira \& Romero, 2017).

Assembly and handling are one of the basic and most widespread applications of robotic systems in industry. Modern means of information technology make it possible to create realistic 3D simulations for almost any complex automation systems. Users perceive the kinetic dynamics of cyber-physical systems visually, through virtual models. Today, simulation is an important tool in the production and development of products, for fast and low-cost analysis of new solutions, methods, and processes. Depending on the task in question, simulation systems come into play, which differ from each other in terms of the information detail level and its acquisition methods. Realistic simulation systems are also used in the situations where real automation systems would reach their limits (Heimann \& Guhl, 2020), (Zheng, et al., 2021).

\section{PROBLEM AREA ANALYSIS}

The subject of interest of the paper is a robotic cell of Robot assembly station (RAS), built based on the (MPS) by FESTO ${ }^{\circledR}$ modular production system (Festo, 2007). The robotic cell is part of a complex heterogeneous multi-robotized workplace in the Laboratory of Control Systems at Institute of Applied Informatics, Automation and Mechatronics, Faculty of Materials Science and Technology in Trnava (Fig. 1) (Juhás \& Juhásová, 2020). RAS represents a robotic cell using various modules of the MPS system, the main parts of which are the Mitshubishi Melfa RV-2FB robotic arm with the CR750-D control unit, as well as other modules from the set of MPS. In addition to the main modules, the cell disposes with parts of the pneumatic system, signal communication and cabling, mounting systems, signaling systems, safety systems and operating elements. The station is developed in accordance with the the EU Machinery Directive 2006/42 / ES and DIN EN 60204-1 and DIN EN ISO 12100.

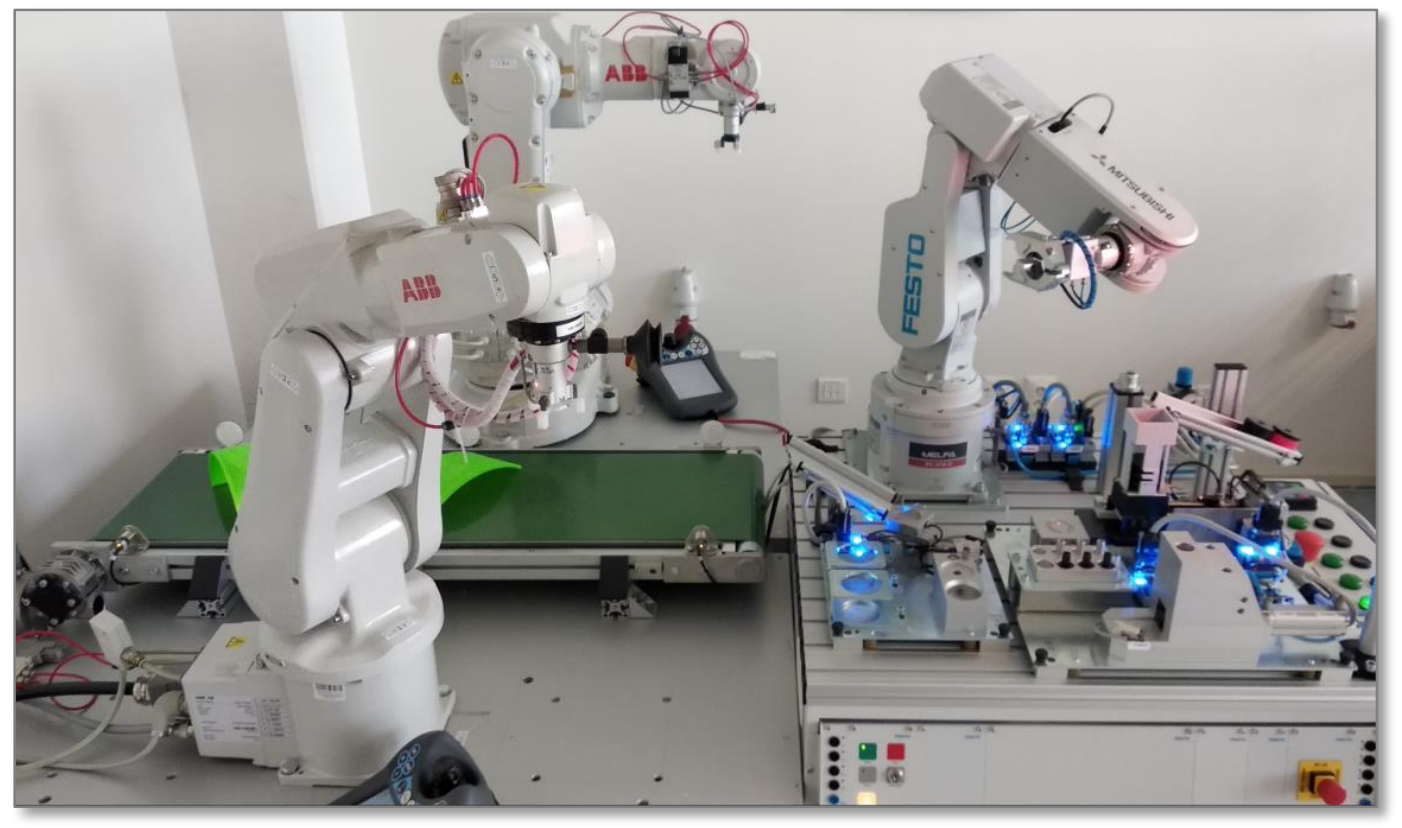

Fig. 1 Complex heterogeneous multi-robotic workplace

The subject of RAS activities is the assembly of pneumatic cylinders. The cylinder consists of four parts: the body, the piston, the spring, and the cap (Fig. 2). The outer diameter of the cylinder is $40 \mathrm{~mm}$. Cylinder body exists in three versions: black, silver and red. The height of the black version is $22.5 \mathrm{~mm}$, the height of the silver and red versions is $25 \mathrm{~mm}$. The piston is available in silver and black, and the height of those parts is also different. While black pistons 
are designed to be mounted only on silver and red bodies, silver, on the other hand, fits only into black cylinders (Table 1) (Charvát, 2018). The intention of the configuration of the production cell is greater variability of the system, considering the requirements arising from the Industry 4.0 concept, especially regarding maximizing the possibilities of product customizability, as shown in Fig. 3 (Pereira \& Romero, 2017), (Enyoghasi \& Badurdeen, 2021).
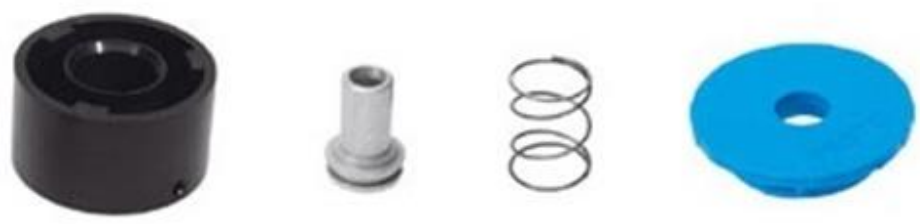

Fig. 2 Components of the assembly process

\begin{tabular}{|l|l|l|l|}
\hline Table 1 Parameters of selected parts of the assembly process \\
\hline & & & \\
\hline
\end{tabular}

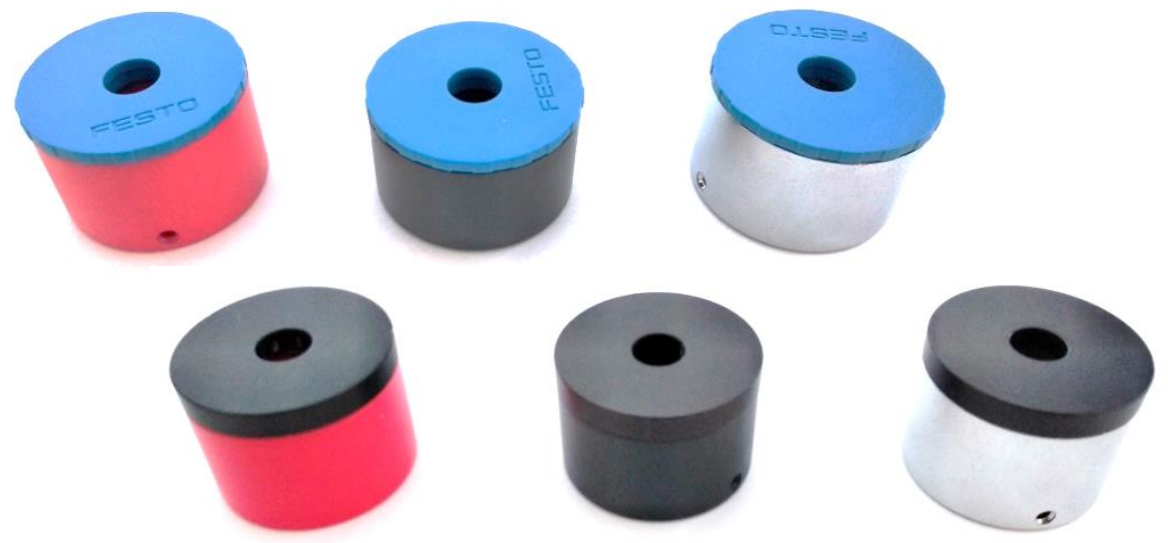

Fig. 3 Product portfolio of the robotic cell

\section{Robot Handling Module}

Robot handling module is one of two more complex station modules which consists of several simple submodules. These are almost all placed on a metal plate with dimensions of $220 \times 220 \mathrm{~mm}$ adapted for easy mounting on the base plate. The reason is easier handling and relocation of the whole module, because subsequently it is not necessary to redefine the positions of individual submodules. The whole module can also be used separately for the process of recognizing the color of cylinder bodies and sorting them into cylinder magazines using a robotic manipulator (Festo, 2007). 


\section{Slide \& Retainer module}

Slide modules (Fig. 4) represent the input and output part of the entire production cycle of a cell. The slide module is in the form of a sliding surface with an adjustable inclination on which the cylinder bodies slide onto the input or output platform. The input platform with a defined position is called the retainer module. The cylinder bodies are placed on the input slide module either manually or by a robotic manipulator, which is a part of this or an adjacent station. The retainer module (Fig. 4) has an optical diffusion sensor that detects the presence of the part. The control unit checks the presence of the part at regular intervals and, if the part is detected, initiates the start of the assembly cycle. The output module has a blanking plug at the end, and is used to store the completed cylinders (Festo, 2007).
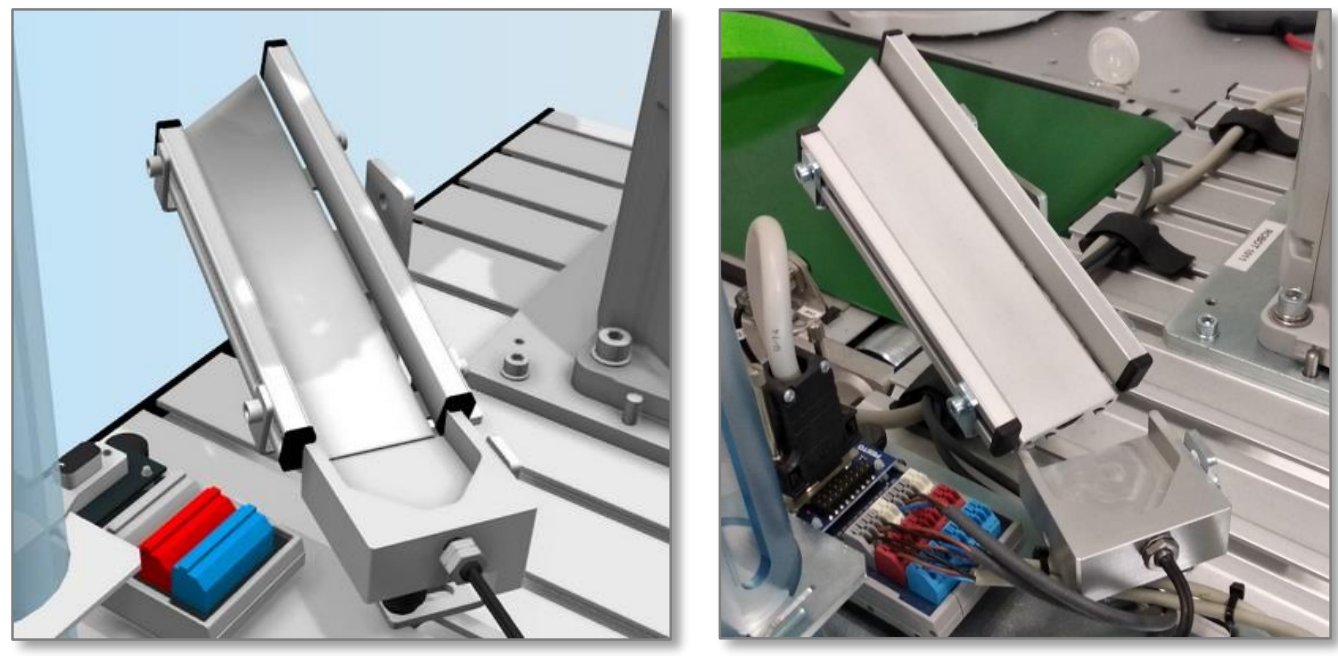

Fig. 4 Slide \& Retainer module

\section{Magazine module}

The magazine module (Fig. 5) is used to store cylinder bodies. The standard module contains two cylindrical magazines, each with a capacity of eight cylinders. This module can be used as an input as well as an output magazine for production parts (Festo, 2007).
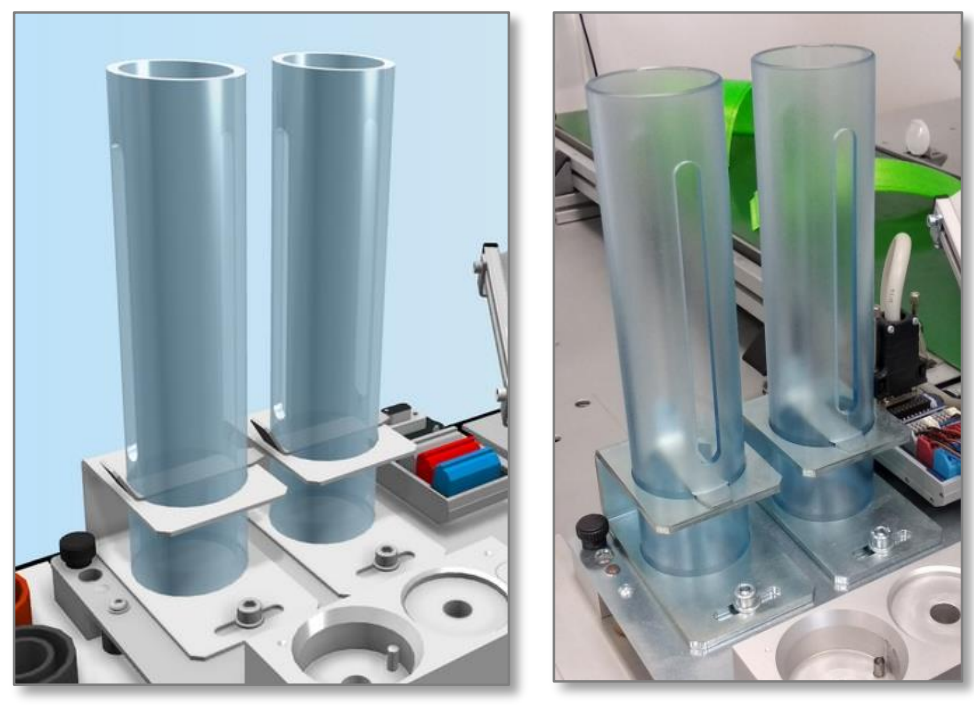

Fig. 5 Magazine module 


\section{Assembly retainer module}

This module (Fig. 6) represents the mounting base of the station and is one of its most important parts. It has a place for storing cylinders and a place with a pin that prevents rotation when assembling other parts. The larger pin is used to store the caps as they are caught by the robot during the assembly cycle. The module also serves to detect the orientation of the cylinder bodies using an optical diffusion sensor.
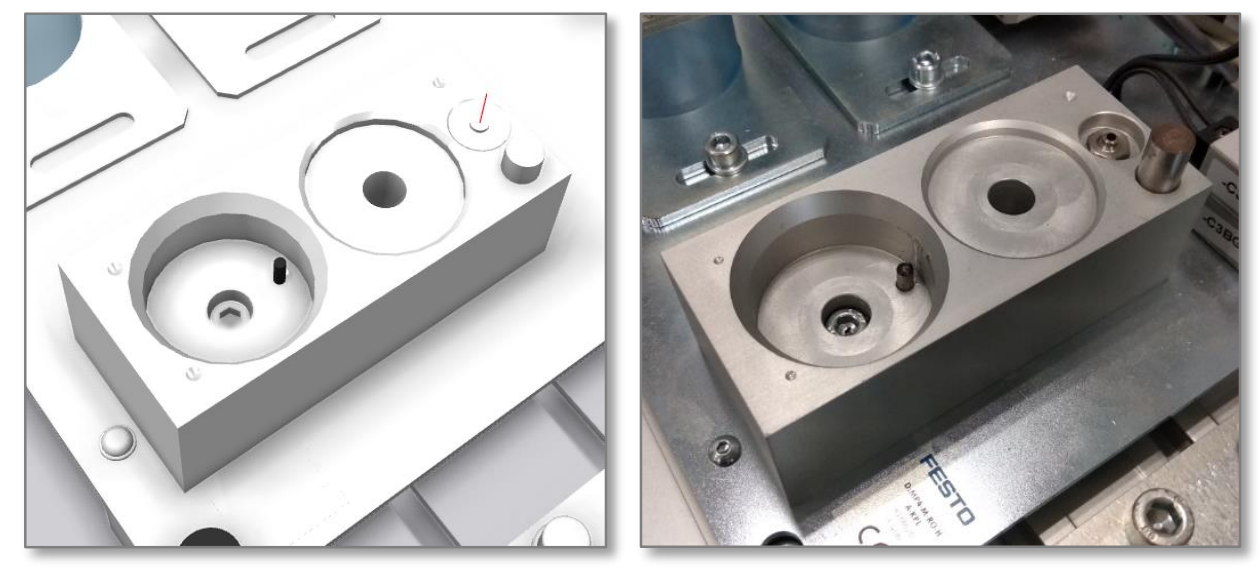

Fig. 6 Assembly retainer module

\section{Robot Assembly Module}

The robot assembly module is the second of the station complex modules. The individual submodules are again placed on a separate metal plate with dimensions $370 \times 325 \mathrm{~mm}$. This time, the module cannot be used on its own, as its task is to provide pistons, springs and cylinder caps from the reservoirs and prepare them for the assembly process (Festo, 2007).

\section{Piston pallet module}

The pallet module (Fig. 7) provides two types of center pistons for pneumatic cylinders. It has eight positions for four black and four silver pistons. In the simulation model, a pallet is represented as a special type of object that has positions for individual production parts defined on the basis of two marginal positions in the first row, the number of rows and the number of pallet locations (Festo, 2007).
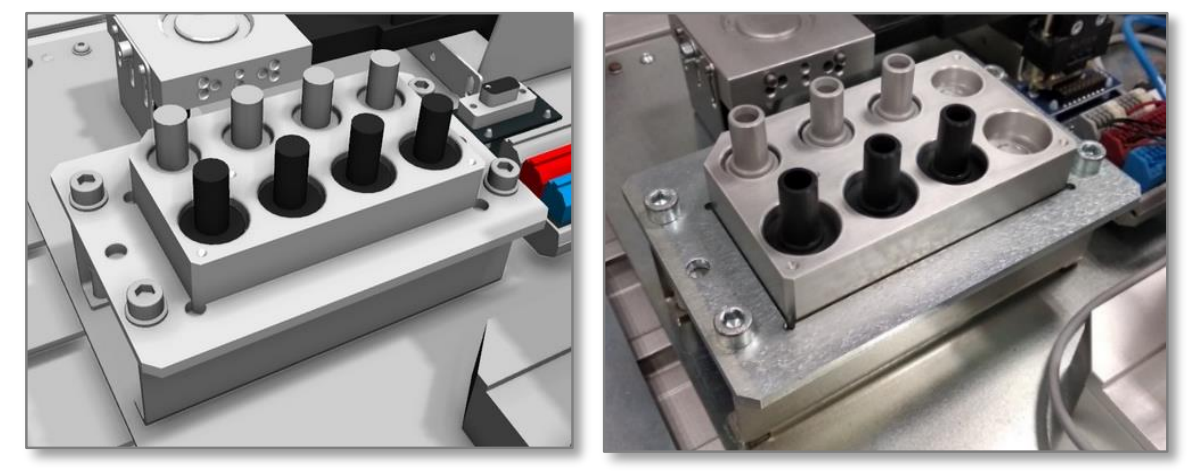

Fig. 7 Piston Pallet module

\section{Spring magazine}

Spring magazine (Fig. 8) is used to store and supply the station with steel springs. The springs are stored in a vertical container from where they are gradually removed. The spring is moved to the robot removal position by extending the double-acting cylinder, which is attached to the jig holding the spring. The station sensors check for the presence of a spring at the pick- 
up point and the end position of the double-acting cylinder of the hopper. These signals serve for ensuring collision-free cooperation between the robotic manipulator and the spring feeder (Festo, 2007).
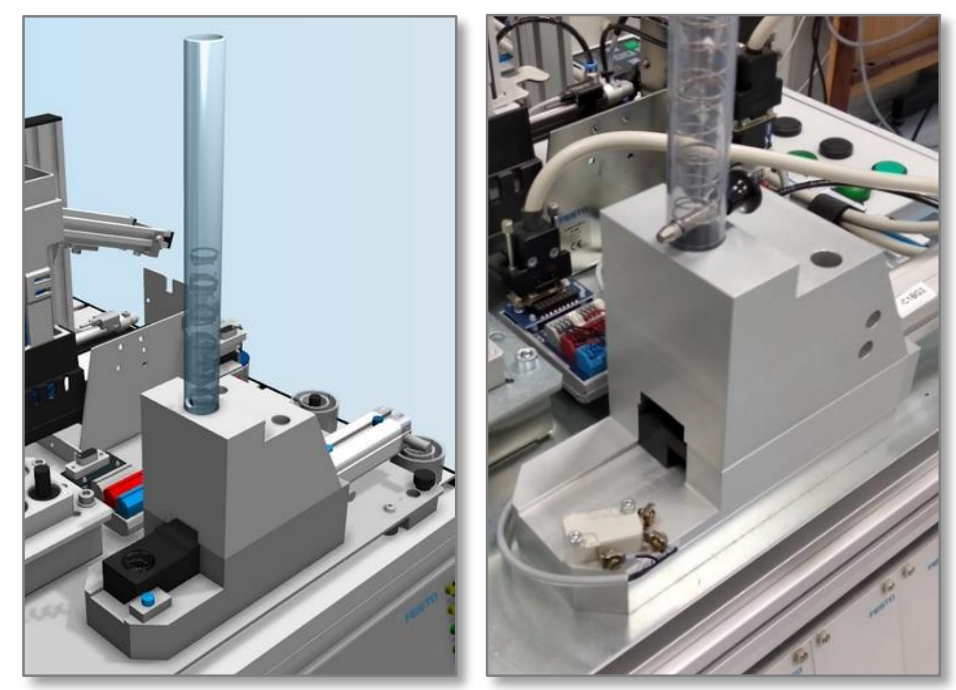

Fig. 8 Spring magazine

\section{Cap magazine}

The magazine of caps (Fig. 9) is used to store and supply the station with cylinder caps. Up to 15 lids can be placed in the container, which are gradually taken. The lid is moved to the removal location by inserting the double-acting cylinder of the hopper, which operates in the inverse mode. The sensors check the presence of the lid at the removal point together with the end position of the container double-acting cylinder (Festo, 2007).

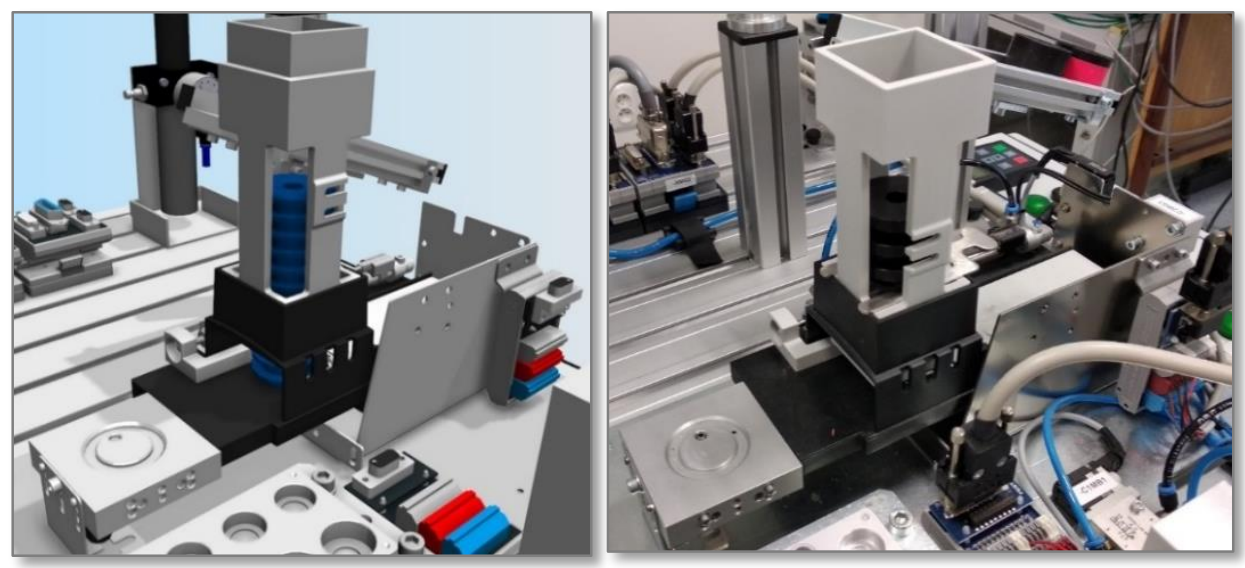

Fig. 9 Cap magazine

\section{Operation of Robotic Cell}

The control of individual modules as well as the assembly of the target product is provided by the Mitshubishi Melfa RV-2FB robotic arm in connection with the control unit CR750-D. The manipulation of objects is enabled by a multifunctional effector in the form of FESTO DHPS-16-A two-finger parallel pneumatic gripper controlled by a solenoid valve of FESTO VUVG-L10-P53C-T-M5-1P3. The working medium - compressed air is transmitted to the end effector by the internal distribution piping of the robotic arm. The end effector is equipped with FESTO SOEG-L-Q30-P-A-S-2L integrated optical sensor connected via an internal electrical wiring to the CR750-D. 
Initialization

Defining the variables, positions, velocities, inputs/outputs, vectors and values of all parameters

\section{*PANEL}

Checking the status of the inputs/outputs of the control panel

\section{*WPART}

Detecting the part presence in the input module

\section{*GETCYL}

Moving the cylinder body to the storage hole of the mounting base

\section{*PLACECYL}

Identifying the cylinder type. Moving the cylinder to the mounting base. Cylinder orientation detection. Placing the cylinder in the mounting hole of the base equipped with a fixing pin.

\section{*GETPIST}

Grasping the piston from the appropriate position on the pallet

\section{*ASSPIST}

Placing the piston to a hole in the cylinder body, located in the mounting hole of the base

\section{*GETSPRG}

Grasping the spring at the moment when the double-acting cylinder of the spring feeder reaches the end position and at the same time the presence of the spring is detected

\section{*ASSSPRG}

Placing the spring to the center hole of the cylinder

\section{*GETCOVER}

Grasping the lid when the double-acting cylinder of the lid feeder reaches the end position and at the same time the presence of the lid is detected.

\section{*ASSCOVER}

Identifying the lid orientation by a mounting base, fitting the lid to the cylinder, fixing the lid by turning it by $60^{\circ}$

\section{*DEPRYPRT}

Grasping the cylinder and placing it on the output storage module

Fig. 10 Robotic cell operation algorithm 
Before starting the assembly cycle, the station component containers must be filled with the required assembly parts. The station is filled in physical form with assembly parts manually, in the simulation; the function of the replicator is used for this purpose. The replicator allows the creation of a virtual interactive object, where after its initialization the required assembly part is generated at a defined location. After filling the station with mounting parts, the station can be started by the virtual or real control console, connected computer, or wired teach pendant.

After the initialization of the variables, the main program is started, which gradually calls the individual subroutines. A description of the subroutines completely describing the operation of the station is shown in Fig. 10 (Festo, 2020), (Mitsubishi Electric, 2005).

\section{ANALYSIS OF PRODUCTION CYCLE SHORTCOMINGS}

\section{Absence of an Inspection Mechanism for the Presence of Parts}

The performed analysis of the whole production cycle of the cell showed that the most significant drawback is the absence of the central piston presence check during its removal operation from the pallet.

Compared to other parts of the production cycle it is clear, that the presence of all parts at the intended location at the appropriate time is monitored by sensors. In the case of cylinder bodies, their presence is detected by an input module sensor or a sensor on the robot jaws. In the case of springs and lids, the control is provided by a set of sensors located directly in the respective magazines. The central piston is thus the only part in which the presence is not checked. The robot thus works with the center piston "blindly", which creates space for errors. If the piston is not in the appropriate place on the pallet, the robot performs the "empty" gripping action. This fact is not detected in any way, the assembly continues, and the result is a faulty product. If the placement of the silver and black pistons on the pallet is confused, the piston would be incorrectly gripped owing to their different heights and thus the positions of the gripping points. This could, for example, damage the part or the jaws of the robot. It is therefore desirable for the station production cycle to have a center piston inspection function.

\section{Redundant Movements of a Robotic Manipulator}

Some subroutines contain redundant positions. This is due to the effort to relatively separate these subroutines. There are several starting positions at the beginning and end of individual subroutines.

\section{Inefficient Parts of the Production Cycle}

The program uses the delay function before using the sensors or jaws of the robot. It ensures safe reading of the value from the sensor or safe opening / closing of the robot jaws.

When feeding the springs through the magazine, the robot waits above the mounting base until the feed piston is fully extended and the sensor detects the presence of the part at the point of removal. Only then the robot moves to the spring feeder and removes the part.

The situation is similar to the lid tray. To remove the lid, the piston must first slide the lid to the removal position and then retract back, as the pull-out tool prevents the robot from removing the part. If the presence of the lid is detected after the piston is retracted, the robot removes the part. 


\section{ACTIONS ENSURING THE ELIMINATION OF IDENTIFIED DEFICIENCIES}

\section{Absence of an Inspection Mechanism for the Presence of Parts - the Solution}

In the case of center pistons, it is necessary to ensure their presence and the correct type. Since the pistons also differ in height, it is advantageous to use the principle of two-phase detection, similar to the inspection of cylinder bodies. In the case of pistons, the situation is different in that the center pistons are in the production cell placed on a pallet. The pallet is a special object for storing up to eight parts that are placed on a common platform and there are equal distances between the individual parts. The advantage of the pallet is that to define the position of removal of all parts, it is sufficient to know the position of the first and last part together with the distance between the individual parts. To access a part on a pallet, it is sufficient to know the pallet number and the serial number of the requested part. This information can be stored, for example, in the form of a program variable.

To determine the inspection positions for the presence and type of piston, it is necessary to consider the fact that the piston jig is divided into two parallel pallets. One has space for four black pistons and the other for four silver pistons.

The serial number of the piston is defined by a variable, which is incremented by one after each completed cycle. The value of the variable is stored in the auxiliary position. The auxiliary position is a vector that has different values in different parts of the program, for example the position of one point from the position list. In this case, it represents the position for removing the piston from the pallet. The robot then removes the appropriate piston from the appropriate position on the pallet during each cycle. Therefore, it is disadvantageous to define the position in the position list for each piston separately. In this case, for each piston of one type, the control position will be the same with respect to the auxiliary position. It is only necessary to ensure that there are no collisions with other parts of the cell when detecting any piston. The inspection position will, of course, be different for black pistons than for silver pistons.

The most advantageous option is to use an optical sensor located in the end effector of the robot to check the presence of the required part. The inspection position for the pistons is chosen so that the sensor beam passes through the center of the piston, is within scanning range and does not collide with other cell parts (Fig. 11). In the first phase of the inspection function, the presence of the part is detected approximately in the middle of its height, in the second phase the sensor is moved to the limit level of the Z-axis value, similarly to the detection of cylinders. The inspection position also satisfies the condition of a suitable distance from the piston, in order to avoid situations where the absence of the required part would cause false detection of a piston of the wrong color on the other side of the pallet.
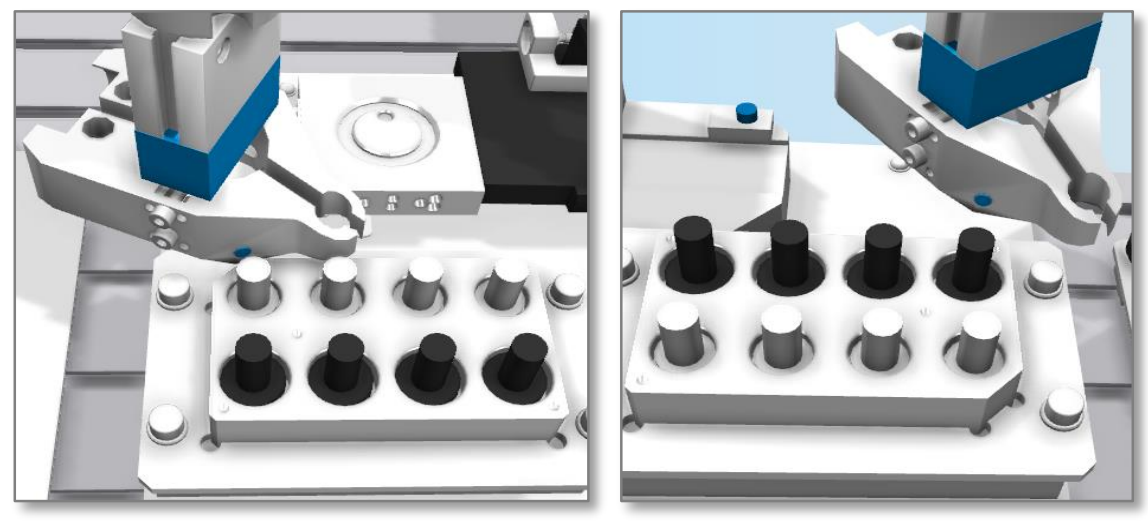

Fig. 11 Piston inspection positions

The inspection position is defined in the program as a vector. This vector is defined by the increment of the $\mathrm{X}, \mathrm{Y}, \mathrm{Z}$ coordinates and the increment of the three angular coordinates. Since 
the inspection positions are determined with respect to the gripping point, the data represent the difference between the removal position and the inspection position on the individual axes and angles. VECPISTS is a vector of presence control for silver pistons, a VECPISTB is a vector for black pistons. The vector named VECPISTC is also used, which in the second phase of the inspection ensures a shift in the $\mathrm{Z}$ axis to the limit level of the piston height (Festo, 2020), (Mitsubishi Electric, 2005).

\section{Redundant Movements of a Robotic Manipulator - the Solution}

Considering the continuity of the subroutines, some of the identified positions turned out to be redundant and were removed from the respective subroutines.

To achieve some positions, the robot first moved up to $200 \mathrm{~mm}$ above the given position and only then moved to the working position. By adjusting this height to $100 \mathrm{~mm}$ or $75 \mathrm{~mm}$, the total movement load of the robot was reduced, which also contributed to reducing the time required to assemble the part (Mitsubishi Electric, 2005).

\section{Inefficient Parts of the Production Cycle - the Solution}

When feeding the springs from the hopper, the robot waited above the mounting base until the feed piston was fully extended and the sensor detected the presence of the part at the removal point. Only then he moved to the spring feeder and removed the part. By modifying the subroutine, the robot moves above the collection point already during the extension of the feed piston. If the condition of part detection is subsequently fulfilled, the robot removes the part without a time delay caused by the preparatory movement and continues with further activity.

In the case of a container with lids, the robot moves to the station in a modified production cycle also during the extension of the piston (Mitsubishi Electric, 2005).

\section{ATTAINED RESULTS}

In addition to modifications to change functionality, a total of 25 modifications were made to increase the efficiency of the robotic cell. Any intervention in the program unrelated to a change in functionality was considered as an efficiency adjustment. It was about editing or deleting commands or moving them to another part of the program.

It should be noted that modifications associated with changing the type of sensor in identifying the cylinders body and detecting the presence of pistons take some time and thus reduce cell productivity and are in contrast to modifications to increase efficiency. Therefore, the measurements of the time required to assemble one part were performed not only on the original and completely modified cell but also on the cell only with efficiency adjustment and on the cell only with modifications related to the change of sensor type and piston inspection. The basic time required to complete one assembly cycle was provided by the original reference station without modification.

\begin{tabular}{|l|l|l|}
\hline \multicolumn{2}{|l|}{ Table 2 Experiments results } \\
\hline \multirow{2}{*}{ Cell configuration } & Assembly time of one part [s] \\
\cline { 2 - 3 } & Silver/Red cylinder & Black cylinder \\
\hline Original configuration & 80.7 & 80.8 \\
\hline $\begin{array}{l}\text { Modified configuration } \\
\text { (inspection + efficiency) }\end{array}$ & 73.2 & 71.78 \\
\hline $\begin{array}{l}\text { Modified configuration } \\
\text { (inspection only) }\end{array}$ & 83.8 & 82.6 \\
\hline $\begin{array}{l}\text { Modified configuration } \\
\text { (efficiency only) }\end{array}$ & 67.5 & 67.6 \\
\hline
\end{tabular}


Measurements showed (Table 2) that the addition of the cylinder and piston detection function extended the assembly cycle time by 3.1 seconds, which represents $3.8 \%$ for the silver or red cylinder and 1.8 seconds, $2.2 \%$ for the black cylinder.

Different times for different colors of parts are due to the inspection position for silver pistons. By placing the silver pistons further from the initial position of the robot and by placing the sensor on the jaws of the robot, the position for checking the silver pistons is more difficult for the robot to reach and therefore takes a longer time.

If these adjustments did not need to be implemented and the modification was aimed exclusively at increasing production efficiency, the time required to assemble the part would be reduced by 13.2 seconds, which represents an increase in efficiency of $18.5 \%$.

The combination of efficiency and both cylinder and piston inspection modifications reduced the total time by 7.5 seconds for silver cylinders and by 9 seconds for black cylinders. This represents a final efficiency increase of $10.3 \%$ for silver and $12.4 \%$ for black cylinders.

The measurement results are valid for the first production cycle and full filling of the pallets. It is clear, that in subsequent cycles within one cell start-up, the duration of the assembly will increase. The reason is that the robot must cover a longer distance to the piston for each additional piston. However, according to measurements, the difference is negligible.

By adding a function to check the presence and type of pistons, the cell is now able to successfully assemble the final product even if the desired piston is missing at the intended pallet location or a piston of the wrong type is in place. The robot detects this error and moves to the next pallet position. This will extend the production cycle time by approximately 0.9 seconds for each missing or incorrect piston.

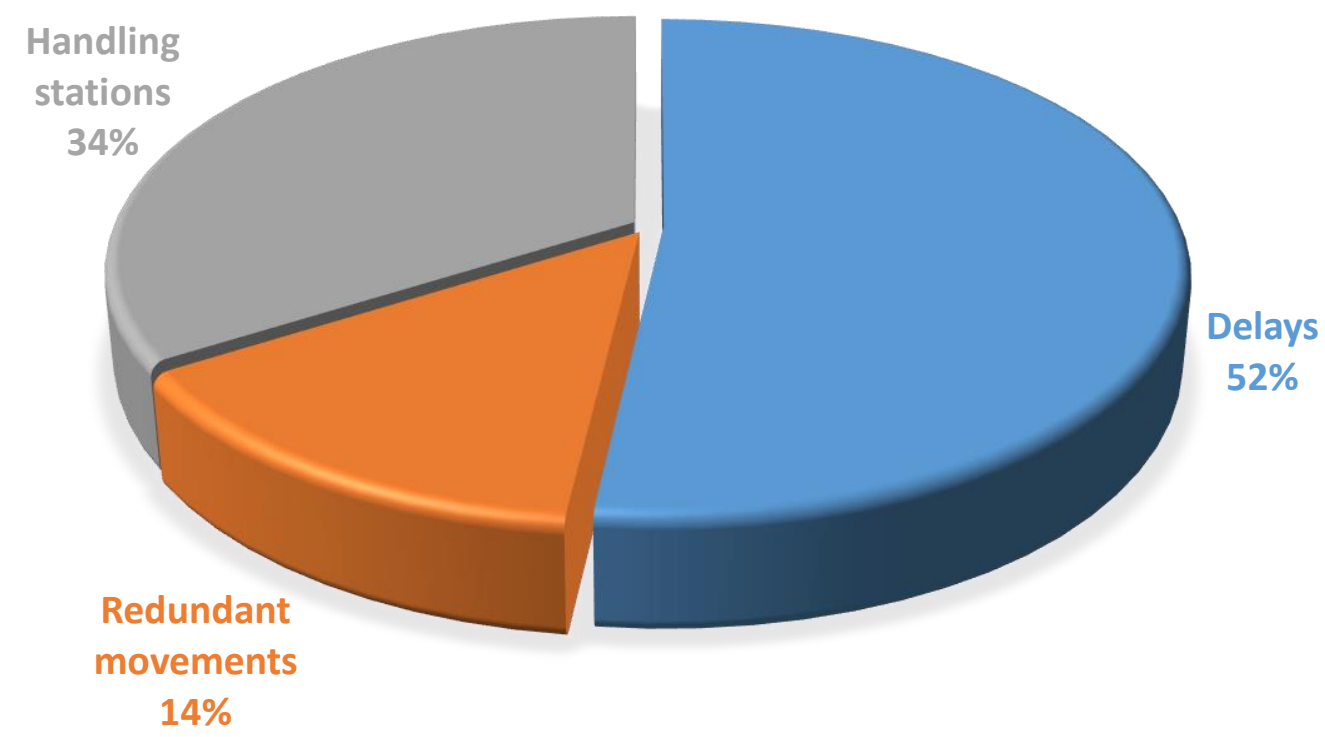

Fig. 12 Impact of individual adjustments on efficiency gains

\section{CONCLUSION}

Reducing delays has proven to be an effective and safe solution. The use of the robot movement in parallel with the preparatory activity of the feeding stations also means a positive impact. The relatively simple modification of the control program has achieved positive results. 
The resulting increase in efficiency of $18.5 \%$ can be assessed as clearly positive, but there is still room for further improvement. In particular, it is a matter of further optimizing the paths and using other types of robot movements, for example, so that the rotation to the final position is performed during the movement. It is important, the designed and implemented modifications ensured increasing efficiencies despite the slowdowns due to cylinder and piston detection functions.

The final average increase in cell efficiency, even with the required functions, reached $11.4 \%$.

\section{Acknowledgement}

This article is a partial result of the Modernizácia laboratórii UVP CAMBO pre vývoj a výskum $v$ oblasti priemyselných podnikov budúcnosti (Modernization of UVP CAMBO laboratories for development and research in the field of industrial enterprises of the future) Project.

This article was written within the framework of the project Interactive Manufacturing @ Schools which has received funding from the European Union's Horizon Europe Research and Innovation Programme under the EIT/EIT Manufacturing/GA 2021 grant agreement.

\section{References}

[1] BARTODZIEJ, C. J., 2017. The concept Industry 4.0. Wiesbaden: Springer Gabler.

[2] ENYOGHASI, C. \& BADURDEEN, F., 2021. Industry 4.0 for sustainable manufacturing: Opportunities at the product, process, and system levels. Resources, Conservation and Recycling, 166, 105362.

[3] FESTO, 2020. CIROS. [Online]. [Accessed 8-2021] Available at: https://ip.festodidactic.com/InfoPortal/CIROS/EN/index.html.

[4] FESTO, C., 2007. MPS Modular Production System. [Online]. [Accessed 8-2021] Available at: www.festo.com.

[5] HEIMANN, O. \& GUHL, J., 2020. Industrial Robot Programming Methods: A Scoping Review. Vienna, Austria, IEEE.

[6] CHARVÁT, D., 2018. Virtualizácia robotickej bunky so zvýšením efektivity jej činnosti. Bakalárska práca.

[7] JUHÁS, M. \& JUHÁSOVÁ, B., 2020. Synchronization of Heterogeneous Multi-Robotic Cell with Emphasis on Low Computing Power. Applied Sciences, pp. 1-20.

[8] Mitsubishi Electric, 2005. MELFA Industrial Robots Instruction manual (Detailed Explanations of Functions and Operations). Ratingen, Germany: Mitsubishi Electric: Ratingen.

[9] PEREIRA, A. C. \& ROMERO, F., 2017. A review of the meanings and the implications of the Industry 4.0 concept. Procedia Manufacturing, 13, 1206-1214.

[10] ZHENG, T., ARDOLINO, M., BACCHETTI, A. \& PERONA, M., 2021. The applications of Industry 4.0 technologies in manufacturing context: a systematic literature review. International Journal of Production Research, 59(6), 1922-1954.

\section{ORCID}

Martin Juhás

0000-0002-8861-1855

Bohuslava Juhásová

0000-0002-5129-8375 